Asian Spine Journal Vol. 6, No. 4, pp 279 283, 2012

http://dx.doi.org/10.4184/asj.2012.6.4.279

\title{
Chondrosarcoma of the Spinous Process: A Rare Presentation
}

\author{
Justin Arockiaraj, Krishnan Venkatesh, Rohit Amritanand, Gabriel David Sundararaj, Gurusamy Nachimuthu
}

Spinal Disorder Surgery Unit, Christian Medical College and Hospital, Vellore, Tamil Nadu, India

Chondrosarcomas are malignant cartilage forming tumours. They form the second most common primary malignant tumour involving the vertebral axis. We present a rare presentation of a secondary chondrosarcoma from the spinous process of lumbar vertebra and discussed its management. The main emphasis is on the rare presentation and the need for awareness and suspicion of the pathology.

Key Words: Chondrosarcoma, Spinous process, Diagnosis, Treatment

\section{Introduction}

Chondrosarcomas are malignant cartilage forming tumours. Up to $60 \%$ of tumours arise in the thoracic spine and the remaining arise from the lumbar spine (20\% to $39 \%)$ and the cervical spine (19\% to 20\%) [1]. The incidence of chondrosarcoma arising from vertebral appendages has not been described in literature. Chondrosarcoma arising from the spinous process is exceedingly rare. There is only one case report of a primary chondrosarcoma arising from spinous process of the first thoracic vertebra (T1) mentioned in the literature [2]. We report a rare presentation of a patient with multiple osteochondromata and a chondrosarcoma arising from the spinous process of 3rd lumbar vertebra treated with marginal excision of the tumour.

\section{Case Report}

A 34-year-old gentleman presented to us with a painless mass over the left paraspinal region incidentally noticed one year earlier. He was not aware of any previous swelling in the same region, or other swellings in the body. Examination revealed a $11 \times 4 \mathrm{~cm}$ non-tender, hard, immobile swelling in the left paraspinal region of the lumbar spine (Fig. 1). There were no palpable swellings elsewhere in the appen- dicular or axial skeleton.

Plain radiographs of the lumbar spine demonstrated. A soft tissue swelling with calcifications, there were mild osteolysis and scalloping seen over the superior border of the spinous process of third lumbar vertebra (Fig. 2). A radiological skeletal survey revealed multiple exostoses in both distal femora, proximal tibiae, proximal humeri, multiple ribs and scapula ranging from 1 to $2 \mathrm{~cm}$ in size (Fig. 3).

Magnetic resonance imaging (MRI) revealed a large lobulated paraspinal mass involving the multifidus muscle extending from L2-L5 spinous process level measuring $4.7 \times 11.5 \mathrm{~cm}$ hypointense in T1 weighted, and hyperintense in T2 weighted/short tau inversion recovery, with no extension into the spinal canal (Fig. 4). A radionucleotide technetium $99 \mathrm{~m}$ bone scan did not show any increased uptake at the level of the lesion.

Computed tomography (CT) showed intra-lesional calcifications within the swelling, which arose from the spinous process of 3rd lumbar vertebra (Fig. 5).

At surgery, a $11 \times 4 \times 4 \mathrm{~cm}$ lobulated mass was seen in the left paraspinal region displacing the muscles, arising from the spinous process of L3 vertebra and indenting the lamina of L3 vertebra (Fig. 6). A marginal resection of the tumour and L3 spinous process was done. The postoperative period was uneventful.

Received May 31, 2011; Revised Jul 5, 2011; Accepted Jul 5, 2011

Corresponding author: Justin Arockiaraj, SV

Spinal Disorders Surgery Unit, Department of Orthopaedics, Christian Medical College,

Ida Scudder road, Vellore, Tamil Nadu 632004, India

Tel: +91-9443114380, Fax: +91416-2232054, E-mail: svjustin@rediffmail.com

Copyright (C) 2012 by Korean Society of Spine Surgery

This is an Open Access article distributed under the terms of the Creative Commons Attribution Non-Commercial License (http://creativecommons.org/licenses/by-nc/3.0/) which permits unrestricted non-commercial use, distribution, and reproduction in any medium, provided the original work is properly cited. Asian Spine Journal • pISSN 1976-1902 eISSN 1976-7846 


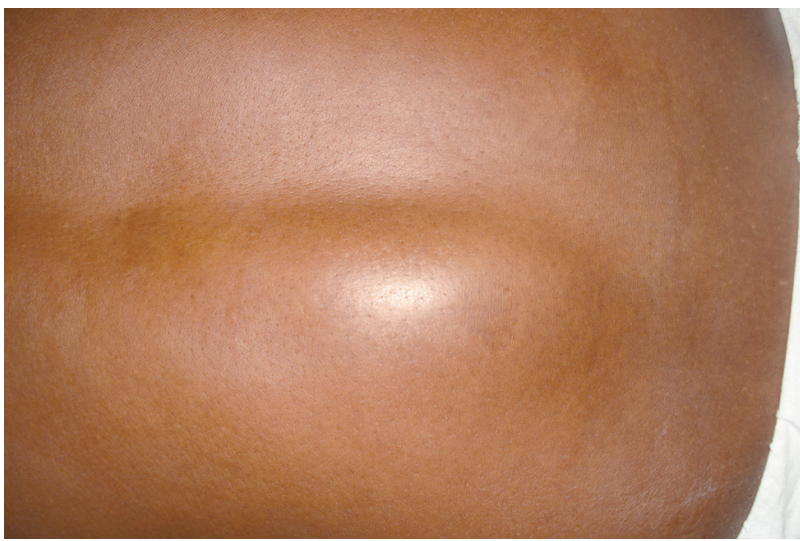

Fig. 1. Clinical photograph shows a mass in the left paraspinal region of the lumbar spine.

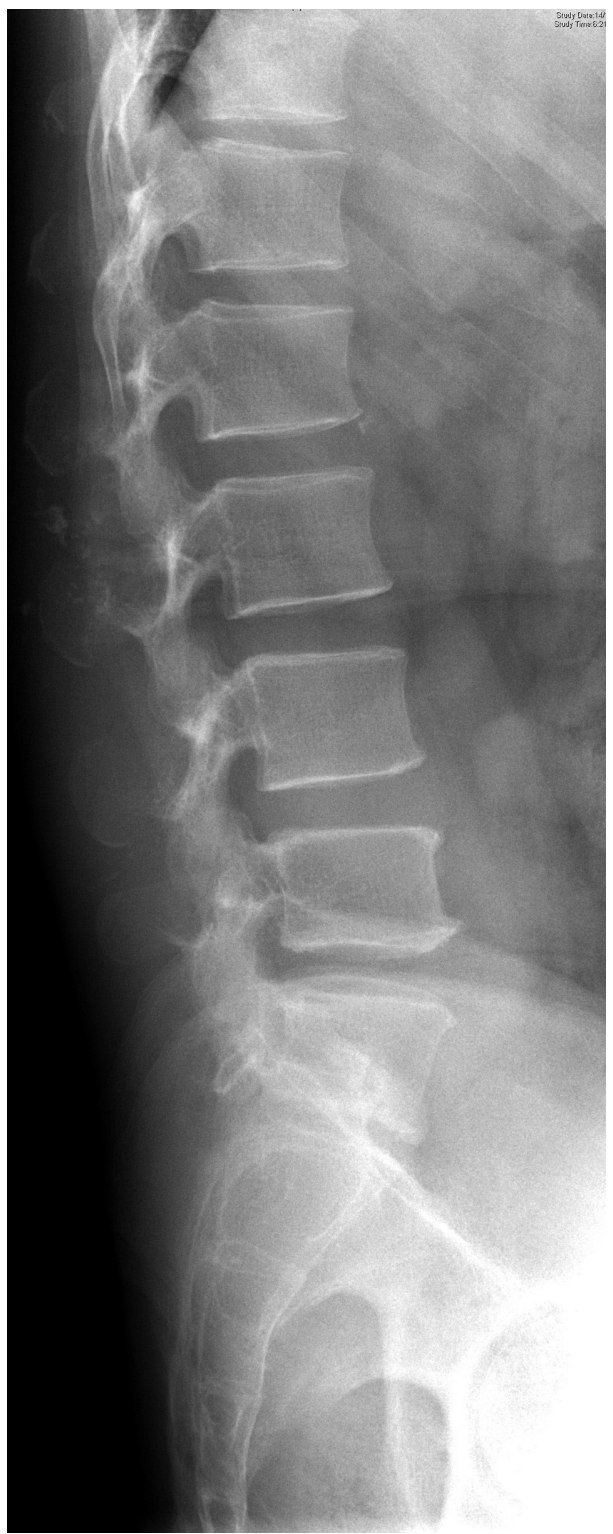

Fig. 2. Plain radiograph reveals stippled calcification and erosion over the spinous process of L3 vertebra.

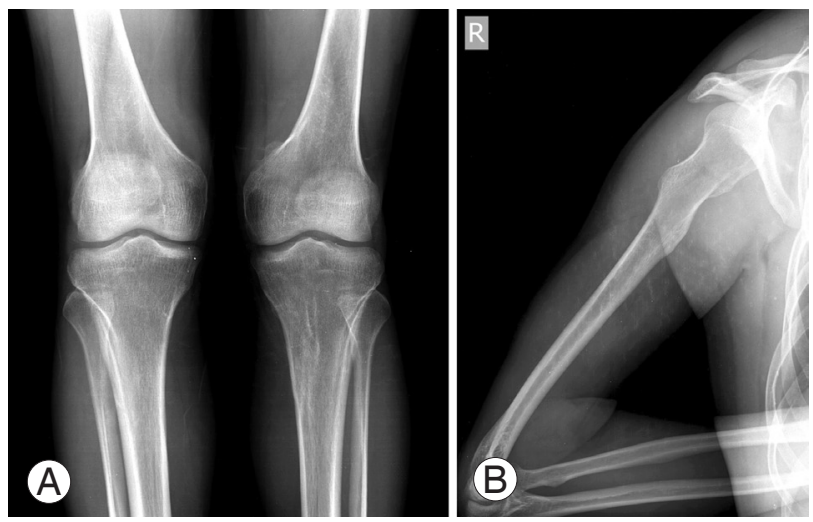

Fig. 3. (A) Multiple osteochondromata seen over bilateral knee joints. (B) Multiple osteochondromata seen over left humerus.

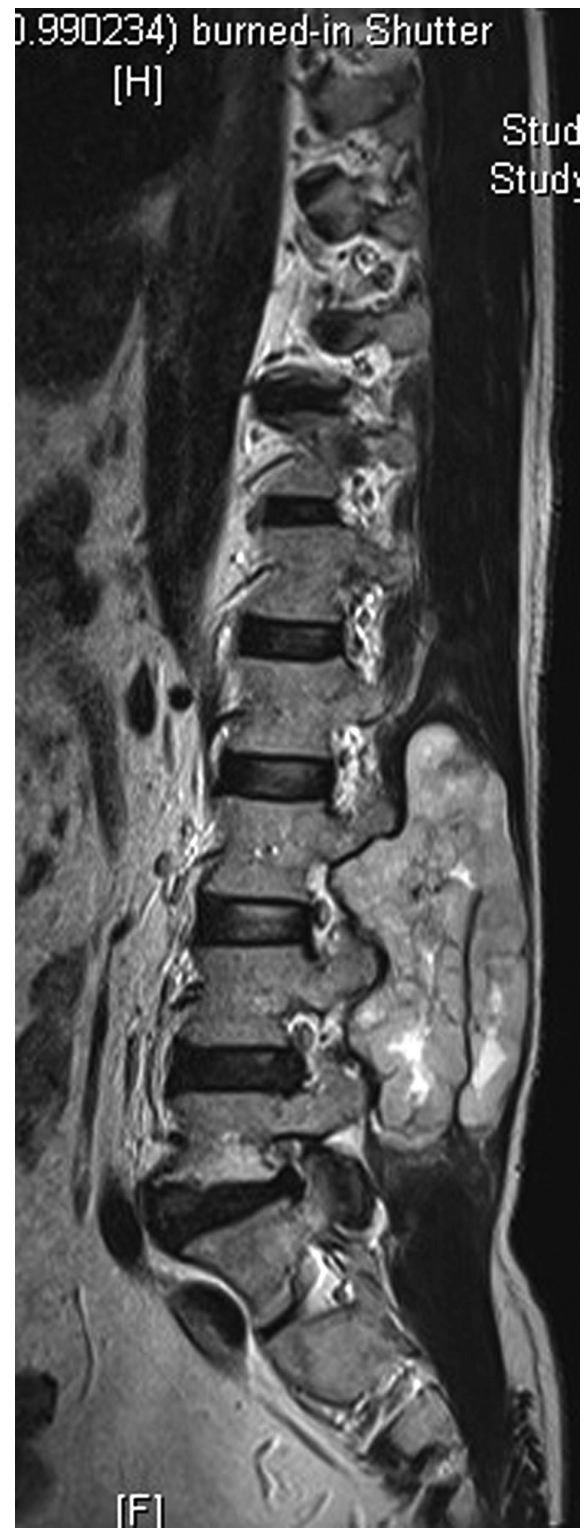

Fig. 4. T2 weighted magnetic resonance imaging scan revealed large lobulated mass around L2-L5 spinous process level. 
Histopathology revealed a low grade classical chondrosarcoma arising from the L3 spinous process. Curettings from the L3 lamina demonstrated the margins to be free of tumour (Fig. 7).

At one year follow-up, patient had no complaints of pain or recurrence of the swelling. Clinical examination revealed no obvious swelling at the operated site. Plain radiographs showed absent spinous process of the lumbar 3rd vertebra with no evidence of any recurrence (Fig. 8). MRI also confirmed the same (Fig. 9).

\section{Discussion}

Chondrosarcoma is a common primary malignant tumour of the bone arising from cartilage cells. Chondrosarcoma is the second most common tumour of the spine after multiple myeloma. Chondrosarcoma may be classified as primary (arising de novo) or secondary (arising from a pre-existing osteochondroma or enchondroma). They may also classified as central (medullary) or peripheral (arising from the surface of the bone). Spinal osteochondromas are extremely uncommon accounting for up to $<1 \%$ to $9 \%$ of all osteochondromas [3-5]. $56 \%$ to $80 \%$ of osteochondromas arise from cervical spine while $20 \%$ to $36 \%$ from thoracic spine [6]. Rarely they arise from the lumbar spine [7].

Chondrosarcomas arising from the vertebral axis usually present as a slowly growing mass with an insidious onset, associated with pain and local tenderness, usually associated with neurological deficits at the time of presentation [1].

Radiological features of chondrosarcoma of the spine do
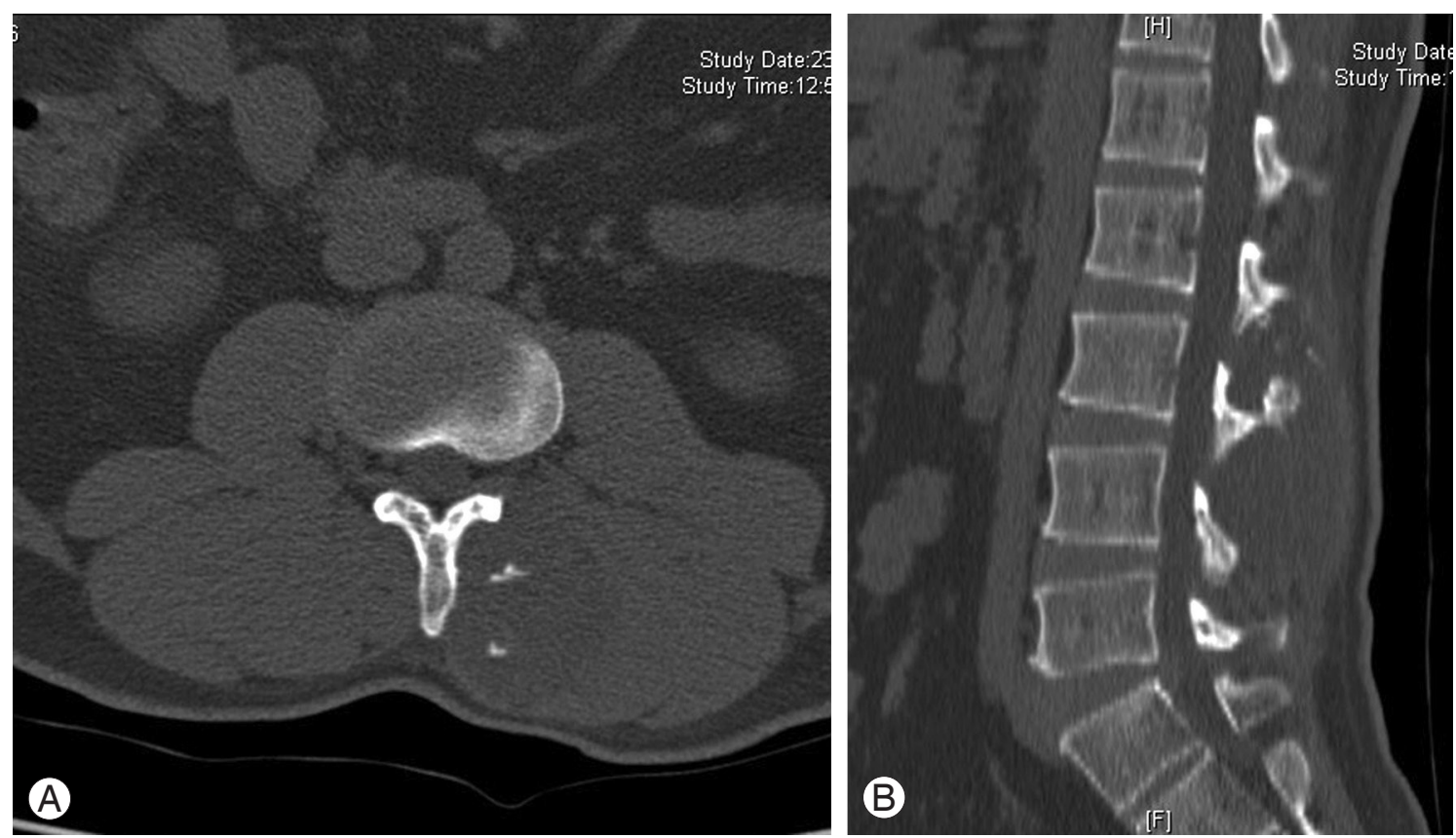

Fig. 5. Computed tomography scan revealed the origin of the mass from the spinous process with scalloping and intra-lesional calcifications withing the mass.
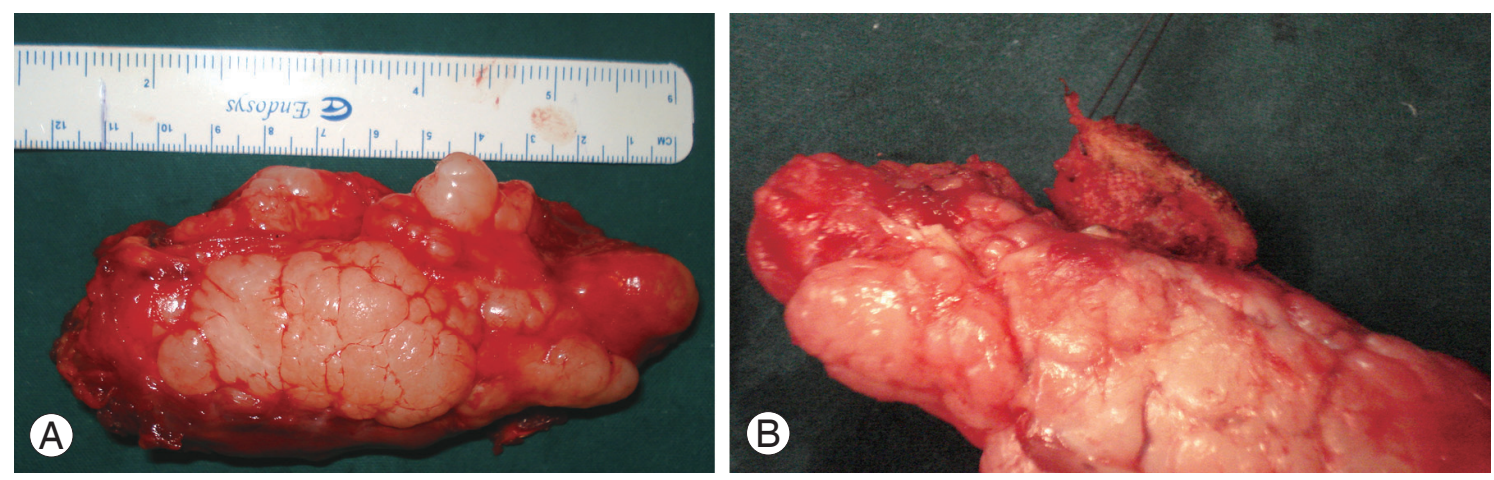

Fig. 6. Gross specimen of the mass chondrosarcoma specimen measuring $11 \times 4 \times 4 \mathrm{~cm}$ along with the spinous process of L3 vertebra. 
not differ from those of rest of the skeleton. Chondrosarcoma usually appear as osteolytic lesions with endosteal scalloping and cartilaginous matrix calcifications. Punctate, pop-corn like calcifications, arcs and ring types have been described for matrix mineralization which is pathognomonic for chondrosarcoma. Chondrosarcoma of the spine usually belong to the mesenchymal or clear cell histological types [1].

Our patient presented with a painless mass incidentally noticed with neither neurological symptoms nor clinical signs of malignancy. The plain radiological and other imaging studies showed classical features of a chondrosarcoma. Histopathology revealed a classical low grade chondrosarcoma unlike the described histological varieties of chondrosarcoma involving the spine.

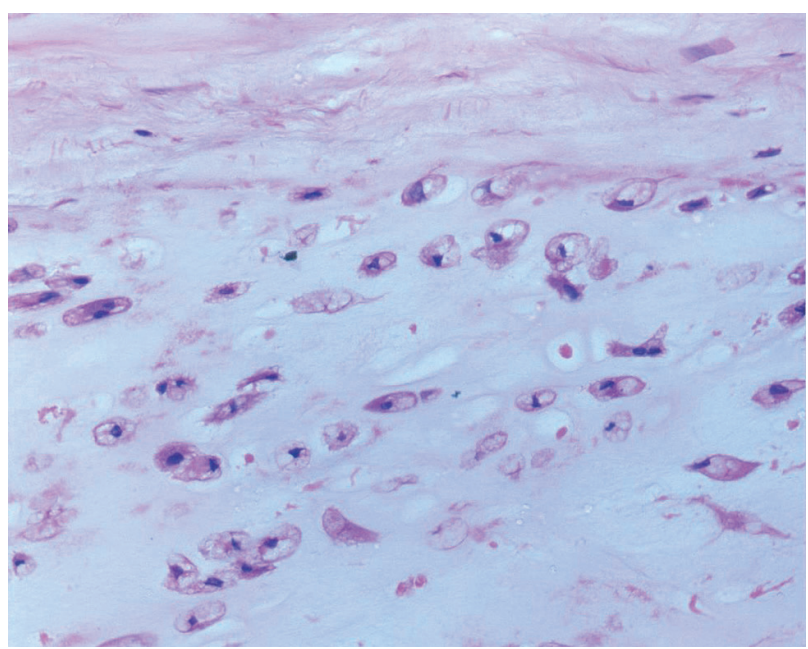

Fig. 7. Histology reveals cellular cartilaginous tumour with moderate nuclear pleomorphism and binucleation-classical low grade chondro-sarcoma $(\mathrm{H} \& \mathrm{E}, \times 40)$.

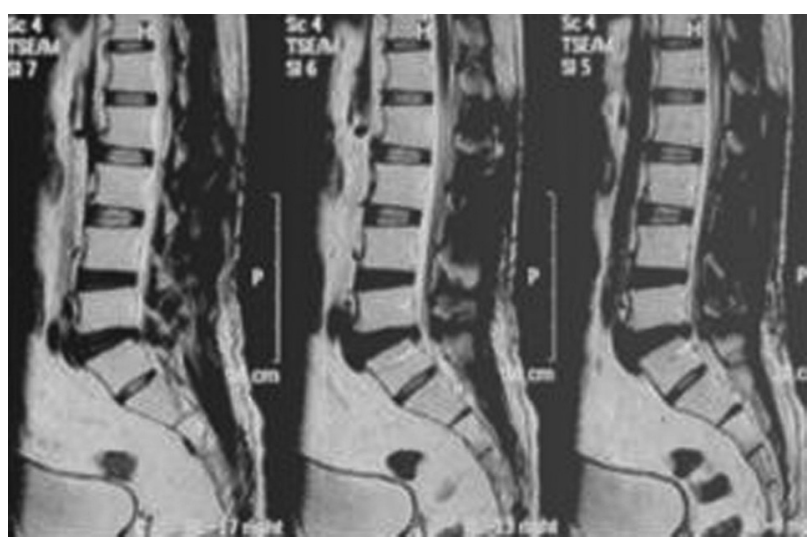

Fig. 9. Magnetic resonance imaging scan of the lumbar spine-T2 weighted sagittal scan with no evidence of tumour recurrence.
The only other reported case is a chondrosarcoma of the spinous process arising from the thoracic (T1) vertebra, presenting with a painful mass and neurologic symptoms. Radiography had revealed lytic destruction of posterior elements mainly spinous process. The CT scan showed destruction of laminae and spinous process (centered within the spinous process) with encroachment into the spinal canal [1].

We present our case as a unique presentation of a spinal

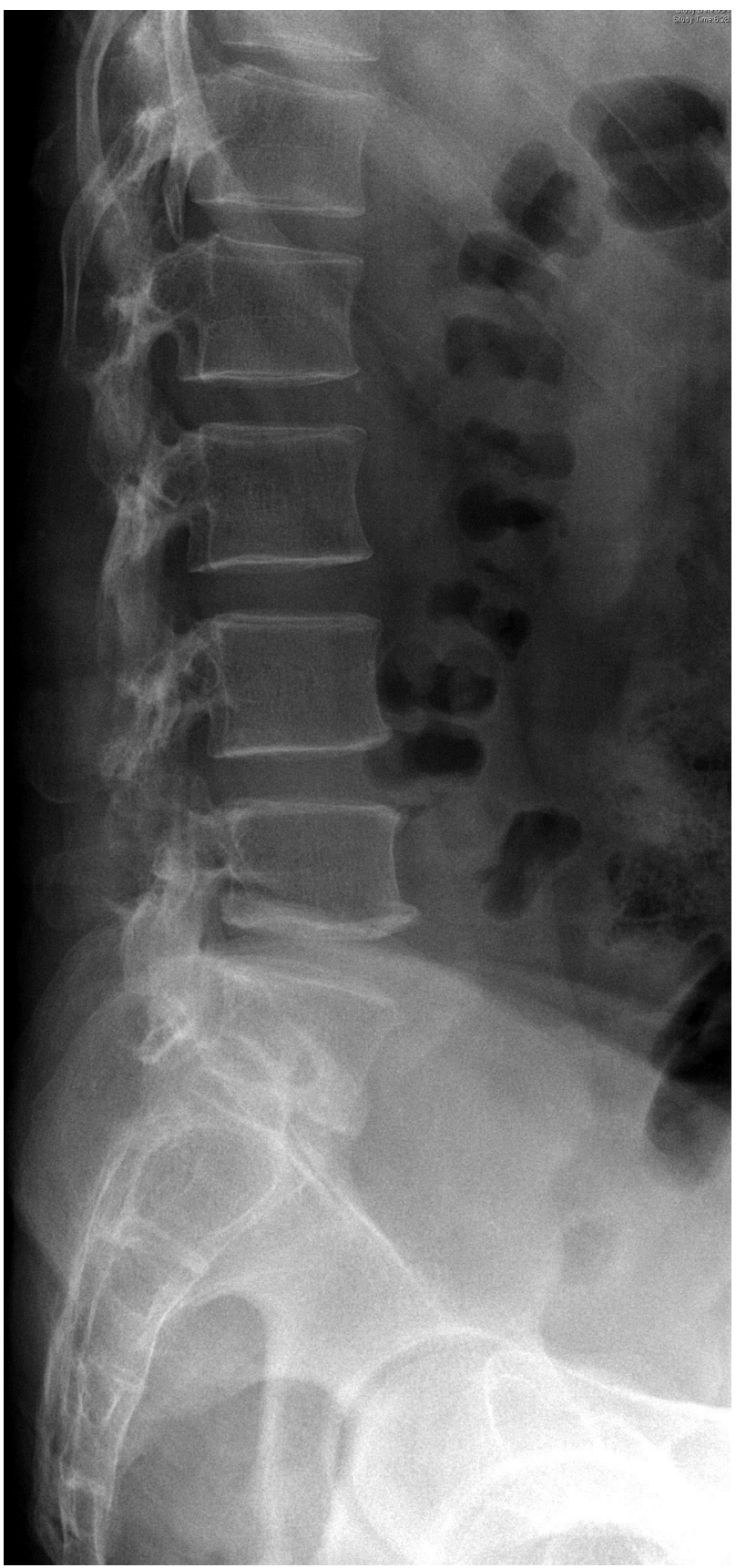

Fig. 8. Plain radiographs-1 year follow-up with no evidence of recurrence. 
chondrosarcoma, in view of its rarity, unusual site of origin and histological features of a classical chondrosarcoma.

\section{REFERENCES}

1. Chow WA. Update on chondrosarcomas. Curr Opin Oncol 2007;19:371-6.

2. Lewis DR Jr, Resnik CS, Aisner SC, Levine AM. Case report 879: chondrosarcoma of the spinous process. Skeletal Radiol 1994;23:677-9.

3. Solomon L. Hereditary multiple exostosis. J Bone Joint Surg Br 1963;45:292-304.
4. Bess RS, Robbin MR, Bohlman HH, Thompson GH. Spinal exostoses: analysis of twelve cases and review of the literature. Spine (Phila Pa 1976) 2005;30:774-80.

5. Solomon L. Hereditary multiple exostosis. Am J Hum Genet 1964;16:351-63.

6. Sharma MC, Arora R, Deol PS, Mahapatra AK, Mehta VS, Sarkar C. Osteochondroma of the spine: an enigmatic tumor of the spinal cord: a series of 10 cases. J Neurosurg Sci 2002;46:66-70.

7. Gürkanlar D, Aciduman A, Günaydin A, Koçak H, Celik N. Solitary intraspinal lumbar vertebral osteochondroma: a case report. J Clin Neurosci 2004;11:911-3. 